\title{
Anterior ischaemic optic neuropathy: recurrent episodes in the same eye
}

\author{
ROY W. BECK, ${ }^{1 *}$ PETER J. SAVINO, ${ }^{12}$ NORMAN J. SCHATZ, ${ }^{12}$ \\ CRAIG H. SMITH, ${ }^{1 *}$ AND ROBERT SERGOTT ${ }^{2}$ \\ From the ${ }^{1}$ Neuro-Ophthalmology Unit, Wills Eye Hospital, and the ${ }^{2}$ Departments of Neurology \\ and Ophthalmology, University of Pennsylvania School of Medicine, Philadelphia, Pennsylvania, USA
}

\begin{abstract}
SUMMARY Anterior ischaemic optic neuropathy is characterised by a sudden, painless loss of vision, optic disc oedema, and nerve fibre bundle visual field defects. It may be associated with giant cell arteritis but is usually idiopathic. Although subsequent involvement of the second eye is common, more than one episode in the same eye is extremely rare. Four patients with recurrent anterior ischaemic optic neuropathy in the same eye are described.
\end{abstract}

Anterior ischaemic optic neuropathy (AION) is the result of infarction in the prelaminar portion of the optic nerve. It may be due to giant cell arteritis or may occur idiopathically. Visual loss is typically sudden and remains stable, without subsequent deterioration or improvement. Although involvement of the fellow eye is common, second ischaemic episodes in the same eye are extremely rare. We report here 4 cases of recurrent AION in the same eye (Table 1).

\section{Case reports}

\section{CASE 1}

A 61-year-old man reported the sudden onset of a cloud over the lower field of vision in his right eye. He had untreated chemical diabetes mellitus and mild hypertriglyceridaemia. Visual acuity was 6/12 OD and $6 / 6$ OS. An afferent pupillary defect and an inferior altitudinal visual field defect were present in the right eye. The right optic disc had pallid swelling superiorly, with a telangiectatic pattern of fine vessels on its surface (Fig. 1a); the left disc and field were unremarkable. Intraocular tension, systemic blood

\footnotetext{
* Dr Beck is currently with the Department of Ophthalmology, Neurology and Neurosurgery, University of Michigan School of Medicine, Ann Arbor, Michigan, and Dr Smith is with the Department of Neurology, University of Washington, Seattle. Washington.

Correspondence to Roy W. Beck, MD, Department of Ophthalmology, Scott Turner Building, 1010 Wall Street, Ann Arbor, Michigan 48109, USA.
}

pressure, and serum glucose were normal. Serum triglycerides were $275 \mathrm{mg} / \mathrm{dl}(3.1 \mathrm{mmol} / \mathrm{l})$ (normal 50-175 $(0.56-1.98 \mathrm{mmol} / \mathrm{l}))$ and erythrocyte sedimentation rate (ESR) by the Westergren method was $13 \mathrm{~mm} / \mathrm{h}$. A diagnosis of nonarteritic ischaemic optic neuropathy was made. No treatment was instituted.

His vision remained unchanged for 3 weeks, when he experienced a second episode of sudden visual loss in his right eye, this time in the superior field. Acuity was 6/240 OD with only an island of visual field remaining in the superior nasal quadrant. The superior portion of the right disc was now pale, but most of the swelling had resolved, and dilated vessels were no longer present on its surface. The inferior portion of the disc, which had previously been normal, now had pallid oedema with haemorrhages in the adjacent nerve fibre layer (Fig. 1b). A repeat ESR was $10 \mathrm{~mm} / \mathrm{h}$. No therapy was instituted.

\section{CASE 2}

A 59-year-old man reported the sudden loss of vision in the inferior visual field of his right eye. He was otherwise well and his medical history was not remarkable. Visual acuity was 6/9 OD and 6/6 OS. An afferent pupillary defect and an inferior altitudinal visual field loss were found in the right eye. The right disc was pale and oedematous superiorly (Fig. 2a); the left disc and field were unremarkable. The intraocular tension, serum glucose, and ESR $(21 \mathrm{~mm} / \mathrm{h})$ were normal. Systemic blood pressure was 190/110 $\mathrm{mmHg}$. A diagnosis of nonarteritic ischaemic optic neuropathy was made. Antihypertensive treatment 
Table 1 Clinical features of 4 patients with recurrent $A I O N$ in the same eye

\begin{tabular}{|c|c|c|c|c|c|c|c|}
\hline \multirow{2}{*}{$\begin{array}{l}\text { Patient } \\
\text { no./agel } \\
\text { sex }\end{array}$} & \multirow[t]{2}{*}{ Eye } & \multicolumn{2}{|c|}{ Initial episode } & \multirow{2}{*}{$\begin{array}{l}\text { Inter- } \\
\text { vening } \\
\text { period }\end{array}$} & \multicolumn{2}{|c|}{ Second episode } & \multirow{2}{*}{$\begin{array}{l}\text { Medical } \\
\text { conditions }\end{array}$} \\
\hline & & Visual field & Disc & & Visual field & Disc & \\
\hline $1 / 61 / \mathrm{M}$ & OD & & $\begin{array}{l}\text { Oedematous } \\
\text { superiorly }\end{array}$ & 3 weeks & & $\begin{array}{l}\text { Oedematous } \\
\text { inferiorly }\end{array}$ & $\begin{array}{l}\text { Borderline AODM, } \\
\text { mild hypertri- } \\
\text { glyceridaemia }\end{array}$ \\
\hline $2 / 59 / \mathrm{M}$ & OD & & $\begin{array}{l}\text { Oedematous } \\
\text { superiorly }\end{array}$ & 3 weeks & & $\begin{array}{l}\text { Oedematous } \\
\text { inferiorly }\end{array}$ & Hypertension \\
\hline $3 / 48 / \mathrm{M}$ & OD & & $\begin{array}{l}\text { Oedematous } \\
\text { superiorly }\end{array}$ & 1 week & & $\begin{array}{l}\text { Oedematous } \\
\text { inferiorly }\end{array}$ & $\begin{array}{l}\text { Mild hypertri- } \\
\text { glyceridaemia }\end{array}$ \\
\hline $4 / 52 / \mathrm{M}$ & OS & & $\begin{array}{l}\text { Diffuse } \\
\text { oedema }\end{array}$ & 45 months & & $\begin{array}{l}\text { Diffuse } \\
\text { oedema }\end{array}$ & Hypertension \\
\hline
\end{tabular}

was begun, but no specific therapy for the optic neuropathy was instituted.

Three weeks later the patient noted further sudden visual loss in his right eye. Visual acuity was reduced to hand movements with only an area of visual field in the superior nasal quadrant remaining. The right disc was now diffusely pale and oedematous, more so inferiorly, and new haemorrhage was present in the inferior peripapillary nerve fibre layer (Fig. 2b). A repeat ESR was $18 \mathrm{~mm} / \mathrm{h}$. He was treated with $60 \mathrm{mg}$ of prednisone a day by mouth, which was tapered over a 2-week period, but he noted no improvement in vision.

Four months later visual function was unchanged and the right disc was diffusely pale.

\section{CASE 3}

A 48-year-old man reported the sudden onset of an area of blurring in the lower temporal quadrant of the right visual field. He was otherwise well and his medical history was not remarkable.
Visual acuity was 6/7.5 OD and 6/6 OS. An afferent pupillary defect and a relative inferior altitudinal visual field defect were present in the right eye. The superior portion of the right optic disc had pallid oedema with haemorrhages in the adjacent nerve fibre layer. Drusen were evident in the left optic disc, but the visual field in that eye was normal. Intraocular tension, serum glucose, systemic blood pressure, and ESR $(18 \mathrm{~mm} / \mathrm{h})$ were normal. Serum triglycerides were $260 \mathrm{mg} / \mathrm{dl} \quad(2.9 \mathrm{mmol} / \mathrm{l}$ (normal 50-175 (0.56-1.98 mmol/l)). A diagnosis of nonarteritic ischaemic optic neuropathy was made. No therapy was instituted.

One week later the patient experienced a second episode of sudden visual loss in the right eye. Visual acuity remained $6 / 7 \cdot 5$, but there was now a marked loss of the superior visual field. The previously normal inferior portion of the disc had pallid oedema and new linear haemorrhages. A repeat ESR was 16 $\mathrm{mm} / \mathrm{h}$. Cerebral arteriography and echocardiography were normal. He received no treatment. 


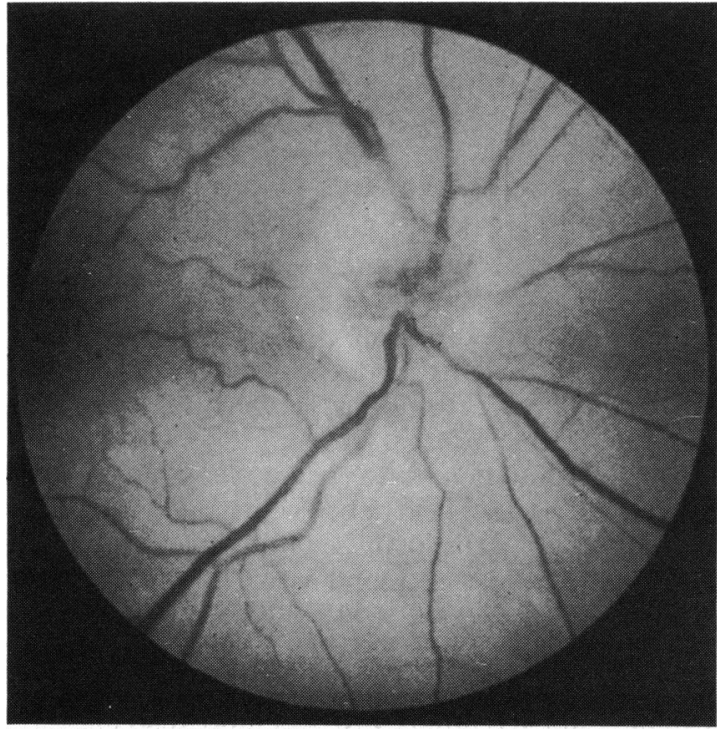

Fig. 1a

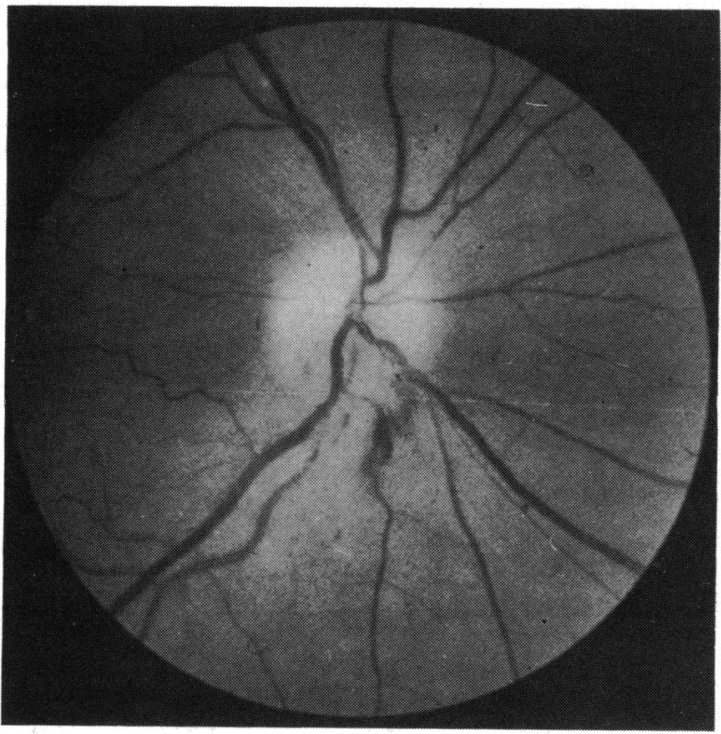

Fig. 1b

Fig. 1 Case 1. (a) Right optic disc shows oedema superiorly with dilated vessels. The inferior portion of the disc appears normal. (b) Three weeks later the inferior portion of the disc is now oedematous with peripapillary haemorrhages. The superior portion of the disc is pale without oedema.

Three years later there was no significant change in visual function. The right disc became diffusely pale.

\section{CASE 4}

A 52-year-old man reported the sudden onset of a 'blind spot' in his left eye. He was otherwise well and

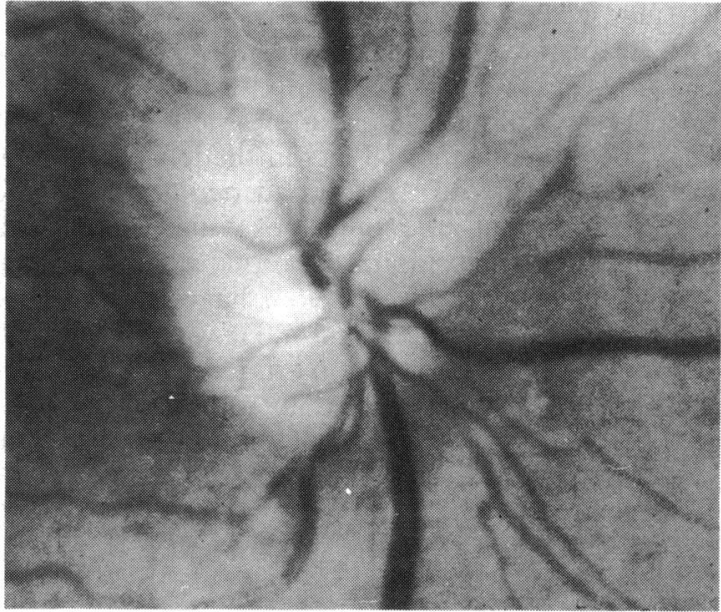

Fig. 2a

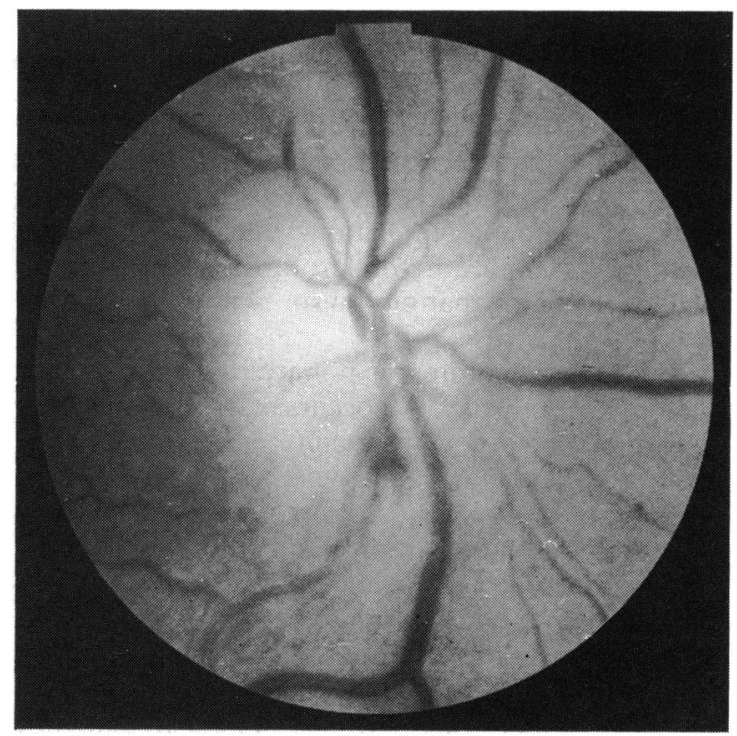

Fig. 2b

Fig. 2 Case 2. (a) Right optic disc is oedematous superiorly; inferiorly the disc appears normal. (b) Three weeks later the inferior portion of the disc is now oedematous while the superior portion appears pale with only minimal oedema.

his medical history was unremarkable. Visual acuity was $6 / 6 \mathrm{OD}$ and $6 / 7.5 \mathrm{OS}$ with a left inferior arcuate defect demonstrable on perimetry. The left disc was diffusely oedematous, with linear haemorrhages in the adjacent nerve fibre layer. The right fundus and visual field were unremarkable. Intraocular tension. serum glucose, and ESR $(20 \mathrm{~mm} / \mathrm{h})$ were normal. The systemic blood pressure was $150 / 95 \mathrm{mmHg}$. Cerebral arteriography gave normal results. He was 
treated with $60 \mathrm{mg}$ of prednisone daily by mouth, which was tapered over one month, but he had no improvement in vision.

Forty-five months later he experienced a second episode of sudden visual loss in the left eye. Visual acuity was reduced to $6 / 30$ and perimetry showed further loss of the inferior visual field with involvement of fixation. The optic disc was again diffusely swollen, with haemorrhages at the disc margin. The ESR was $21 \mathrm{~mm} / \mathrm{h}$. He was treated with $60 \mathrm{mg}$ of prednisone daily by mouth, tapered over one month, but his vision did not improve.

Fifteen months later he developed ischaemic optic neuropathy in his right eye. His left eye had not changed.

\section{Discussion}

The aetiology of AION, when it is not associated with giant cell arteritis, is presumed to be secondary to atherosclerotic changes in the optic disc vasculature, ${ }^{12}$ but pathological confirmation of this is lacking. About half the patients have hypertension, ${ }^{34}$ but the remainder lack any specific disease. Diabetes mellitus does not occur any more frequently than it does in the general population. ${ }^{34} \mathrm{Few}$ patients have advanced systemic atherosclerotic disease, and there is good evidence that embolism is not a significant factor. ${ }^{34}$

The clinical features of nonarteritic AION have been well described. ${ }^{3-13}$ It occurs mainly between the ages of 50 and 70 . Visual acuity may be normal or decreased, depending upon whether the fibres of the papillomacular bundle are involved. Visual field defects are commonly of the nerve fibre bundle type, with altitudinal and arcuate defects being most typical. The inferior visual field is affected more frequently than the superior. The optic disc may be either partly or wholly oedematous, and, although it is typically pale, initially it may appear hyperaemic secondary to capillary dilatation. Streak haemorrhages at the disc margin are common. The visual deficit usually occurs suddenly and then remains stable, without subsequent deterioration or improvement. Oedema of the disc resolves within several weeks, leaving residual pallor, often in a sectoral or altitudinal fashion. No treatment has been found to be efficacious in controlled clinical studies.

Despite a $40 \%$ frequency of AION in the fellow eye $^{3}$ repeat attacks in the same eye are rare. Smith ${ }^{14}$ has stated that it never happens, but other authors have noted that it may occur. ${ }^{912}{ }^{13}$ We have been able to find only 3 descriptions of patients with repeated episodes of AION in the same eye. In a retrospective analysis of 29 patients with idiopathic AION Boghen and Glaser $^{3}$ reported on a 45 -year-old woman who had a second episode of AION 2 years after the first. In a similar review of 48 patients with AION Ellenberger et al. ${ }^{7}$ described one patient who suffered a second episode of AION in each eye. Smith and Goldhammer ${ }^{15}$ reported on a 62-year-old hypertensive man with 2 episodes of visual loss in his left eye 3 years apart. The first produced a small superior temporal paracentral scotoma and the second an inferior nasal visual field defect. Funduscopy 5 days after the second episode of visual loss showed slight dilatation of capillaries in the upper temporal portion of the disc. Fluorescein angiography demonstrated leakage in the same area.

A differentiation must be made between progression of a visual field deficit within a single episode of AION and a distinctly separate second episode. Boghen and Glaser ${ }^{3}$ found visual loss to be progressive to some degree in 11 out of 39 eyes. In most of the patients progression occurred over a period of one to 9 days. Ellenberger $e t$ al. ${ }^{7}$ had no patients in whom visual loss progressed over more than one day. Cullen ${ }^{6}$ found no evidence of progression in any of 19 patients with 'arteriosclerotic' AION. Miller and Smith $^{5}$ described progression of visual loss in one of 11 patients with AION. This patient's visual acuity decreased from $6 / 9$ at the initial examination to $6 / 21$. The time course of the reduction in acuity and its aetiology were not discussed. Shults ${ }^{16}$ reported on a 39-year-old male who developed bilateral consecutive AION in whom visual loss progressed over about one week in each eye.

All 4 of our patients had a definite, documented second episode of AION. The interval between the 2 episodes in the first 3 cases was 3, 3, and 1 week respectively. Despite these relatively short intervals of time the 2 episodes in each patient were distinctly separate. In each case there was an initial sudden loss of inferior visual field which corresponded to an observed oedema of the superior portion of the disc. This field defect remained stable but was followed by a second apoplectic episode of visual loss involving the superior visual field. The inferior portion of the disc, which was initially normal, became oedematous with haemorrhages at the margin, while most of the oedema of the superior portion of the disc had resolved.

In patient 4 almost 4 years elapsed between the 2 episodes of AION. In both episodes there was diffuse disc oedema with haemorrhages in the adjacent nerve fibre layer and involvement of the inferior visual field.

Our 4 patients differ in no way from the accepted clinical profile of AION. Their age range was 48 to 61 and all were in good health, without systemic evidence of significant atherosclerotic disease. The ESR was normal in each patient during each episode, and none had systemic symptoms or signs of giant cell 
arteritis. Two of the patients ( 2 and 4$)$ had mild hypertension, one (3) had mild hypertriglyceridaemia, and one (1) had borderline untreated diabetes mellitus and mild hypertriglyceridaemia. In no patient was there evidence of any other systemic disease or embolic phenomena which may have contributed to optic nerve infarction. Two patients ( 3 and 4) were admitted to hospital and thoroughly examined for a systemic cause of repeated episodes of optic neuropathy, but none was found. Although there was no evidence of giant cell arteritis, two patients ( 2 and 4$)$ received systemic corticosteroids, but neither had improvement in vision.

Why repeated episodes of AION in the same eye should occur so infrequently is not known. One possible explanation is that, having suffered one episode of AION, a patient might be less likely to recognise further visual loss in the same eye, and thus the calculated incidence of recurrent AION in the same eye might be falsely lowered. As evidence against this we detected additional asymptomatic visual field loss in only one of 58 patients with AION whom we have followed up with sequential perimetry for at least 3 years (unpublished data). It is more likely that certain unknown constant features of the structure of the optic nerve head or its blood supply provide the explanation. It is possible that when a portion of the optic disc is infarcted the blood supply which is subsequently shunted away from this area is sufficient to protect the remainder of the disc from a second ischaemic episode.

Two independent episodes of AION may occur in the same eye. Although rare, it does not appear to reflect any underlying systemic abnormality other than those noted in patients with AION in general.
This work was supported in part by a fellowship grant from the Heed Ophthalmic Foundation, Chicago (Dr Beck), and by a postdoctoral research fellowship from Fight For Sight, Inc., New York City (Dr Smith).

\section{References}

1 Lieberman MF, Maumenee AE, Green WR. Histologic studies of the vasculature of the anterior optic nerve. Am J Ophthalmol 1976; 82: 405-23.

2 Hayreh SS. Anterior ischaemic optic neuropathy. I. Terminology and pathogenesis. Br J Ophthalmol 1974; 58: 955-63.

3 Boghen DR, Glaser JS. Ischaemic optic neuropathy. The clinical profile and natural history. Brain 1975; 98: 689-708.

4 Ellenberg C. Ischemic optic neuropathy as a possible early complication of vascular hypertension. Am J Ophthalmol 1979; 88: 1045-51.

5 Miller GR. Smith JL. Ischemic optic neuropathy. Am J Ophthalmol 1966; 62: 103-15.

6 Cullen JF. Ischaemic optic neuropathy. Trans Ophthalmol Soc UK 1967; 87: 759-74.

7 Ellenberger C, Keltner JL, Burde RM. Acute optic neuropathy in older patients. Arch Neurol 1973; 28: 182-5.

8 Eagling EM, Sanders MD, Miller SJH. Ischaemic papillopathy. Clinical and fluorescein angiographic review of forty cases. $\mathrm{Br} \mathrm{J}$ Ophthalmol 1974; 58: 990-1008.

9 Hayreh SS. Anterior ischemic optic neuropathy. New York: Springer, 1975.

10 Hayreh SS. Anterior ischemic optic neuropathy. Arch Neurol $1981 ; 38: 675-8$.

11 François J. Vascular pseudopapillitis: ischemic optic neuropathy. Ann Ophthalmol 1976; 8: 901-19.

12 Miller NR. Anterior ischemic optic neuropathy: diagnosis and management. Bull NY Acad Med 1980; 56: 643-54.

13 Glaser JS. Neuro-ophthalmology. Hagerstown: Harper and Row, 1978: 87-91.

14 Smith JL. In: Smith JL, Glaser JS, eds. Neuro-ophthalmology Symposium of the University of Miami and the Bascom Palmer Eye Institute. St Louis: Mosby, 1973: XI.

15 Smith JL, Goldhammer Y. Hypertensive optic neuropathy. Trans Am Acad Ophthalmol Otolaryngol 1975; 79: 520-3.

16 Shults WT. Ischemic optic neuropathy: some interesting features. Trans Pac Coast Otoophthalmol Soc 1977; 58: 281-98. 